\title{
Green entrepreneurship in India
}

\author{
Y.D. Nayak ${ }^{1 *}$ and A.P. Sahoo ${ }^{2}$ (i) \\ Received 17 July 2021, Revised 29 October 2021, Accepted 20 December 2021, Published online 31 December 2021
}

\section{A B S T R A C T}

Entrepreneurs are credited with playing a key role in wealth creation and economic development. There has been enough focus of empirical literature on linking entrepreneurship and employment generation, reducing income disparity and contributing to balanced regional development. However, the environment catastrophe, world is facing, has made it imminent for the business to find new ways of doing business. Green Entrepreneurship, however nascent, provides a gleam of hope to in the direction of sustainable development. Growing consumer awareness and preference towards environmentally friendly products has also made embedding green concepts in business models a source of competitive advantage. This study is exploratory in nature as it offers insights into the emergence of the concept of green entrepreneurship and its role in the Indian context. Based on available literature, the study proposes a conceptual model explaining a link between various social, environmental and institutional factors and green entrepreneurship, leading to sustainable development. The study also explores current green entrepreneurship scenario in the light of opportunities and challenges by presenting the case studies of successful green ventures in India.

Keywords: Green entrepreneurship, Green innovation, Competitive advantage, Sustainable development

\footnotetext{
${ }^{1}$ Assistant Professor, P.G. Department of Commerce, Khallikote University, Berhampur, Odisha, India

${ }^{2}$ PhD Research Scholar. KSOM, KIIT University, Bhubaneswar, Odisha, India
}

*Corresponding author's email: yajnya.dutta@gmail.com (Y.D. Nayak)

Cite this article as: Nayak, Y.D. and Sahoo, A.P. 2021. Green entrepreneurship in India. Int. J. Agril. Res. Innov. Tech. 11(2): 72-75. https://doi.org/10.3329/ijarit.v11i2.57258

\section{Introduction}

Entrepreneurship is perhaps the most talked about business concept in the last few decades. Although the first comprehensive definition of entrepreneurship was given by Jean Baptiste Say in early $19^{\text {th }}$ Century it is the work of Joseph Schumpeter (1883-1950), who described entrepreneurship as "Creative destruction", which he describes as the continuous process of product and process innovations, leading to replacement of old products by new ones, is the most landmark work in the literature of entrepreneurship (Schumpeter, 1942). Schumpeter's work is also significant as he not only explained the importance of entrepreneurship in business processes but also explained it in macroeconomic context i.e., improvement in productivity, structural adjustments and economic fluctuations and microeconomic context i.e., strategic and technological considerations at the firm level involved in the process of structuring.

Entrepreneurship has been emphasized as the vehicle of economic growth and development, both being correlated but different concepts; it is however, economic development that developing countries like India are eying. Several studies have concluded that there exists a positive correlation between economic development (Melay et al., 2017) and entrepreneurship. Some of the ways that entrepreneurship serves as the vehicle of economic development is by creating and adding value by bearing uncertainties that other economic agents would be neither willing nor able to bear, by generating employment opportunities, by removing regional economic and social disparities, by promoting gender equality, more even development of infrastructure and import substitution.

However, in the face of environmental dangers economies are facing, economic development to be replaced by sustainable economic development and entrepreneurs being the change agents, can be the torchbearers of sustainability. Climate change has not only done irreversible damage to the environment and affected the ecological cycles but also it has endangered the sustenance of the economies. There has been persistent, unbridled and rapid exploitation of natural resources to achieve economic growth. As a consequence of such 
continuous exploitation and unsustainable world economic growth, vital signs such as melting of glaciers, forest fires, rapid increase in earth's temperature and decline in coral reefs indicate that natural environment has reached its limit. Thus, there is an urgent need for adoption of sustainable practices in both consumption and production to try to obtain preservation and balance on economic, environmental and social dimensions. The focus of thinkers has therefore, shifted from making the enterprises greener to addressing the issue of sustainability in businesses right from their inception. Hence, the entrepreneurs who engage in "creative destruction" and are called as change agents should shoulder the responsibility to develop innovative business practices to deal with social and environmental challenges, thus paving way for a sustainable future. A separate category of entrepreneurs, driven by sustainability concerns are garnering attention of the policy makers, researchers and other stakeholders.

The term 'green entrepreneurship' was firstly used by Berle. However, there remains a lot of confusion regarding what is it that makes up 'green entrepreneurship', how can it be defined and how to differentiate it from non-green entrepreneurship? All these questions therefore make it important to undergo extensive analysis of how green entrepreneurs identify new business opportunities, develop their ideas, and convert the ideas into reality, $l \mathrm{au} \mathrm{n} \mathrm{ch}$, and nurture the venture for earning profits. India is as other countries have been rapidly exploiting natural resources for achieving rapid industrialization and economic growth. Therefore, India needs green entrepreneurs who can act as change agents and can help achieving economic growth in a sustainable manner by marrying the twin processes of innovation and sustainability. The purpose should be to provide such an enabling environment that these green entrepreneurs not only get successful but also lead other businesses towards adopting green practices.

Today when every country is focusing on 'sustainable development', the Indian markets are also responding to the phenomenon of climate change, as there is a paradigm shift towards green production and consumption in the recent decades. Consumers' tastes and preferences are shifting towards sustainable products. Increase in per capita Income, Improvement In level of education, changes in lifestyle and growing awareness about environmental concerns may be the causes of this shift. The paradigm shifts in the consumption patterns have led to emergence of green markets in India, that provide huge scope and opportunities for entrepreneurs to design, develop green products and making use of green processes.
Green entrepreneurship is not there only to catering to the shifting consumer demand for sustainable products but also to contribute and be a guide towards achieving sustainable development in the long run. Therefore, green entrepreneurs can be defined as entrepreneurs who identify the connection between innovation and sustainability and achieve competitive advantage by focusing on and selling products that are benefitting to environment. Green products are designed in such a manner that there is lesser use of natural resources, elimination of toxic waste substances that can be harmful to environment and human health, recycling of waste material and reduction in consumption of energy. The role of green entrepreneurs is therefore not only limited to offer answers to the challenges environmental degradation is forcing on the ecology but also to challenge the traditional marketing systems and scenarios to adopt the green perspective.

This study offers insight into the emergence and evolution of green entrepreneurship scenario in India. The next section discusses the enabling factors of green entrepreneurship. The next section presents a conceptual model that explores the inter-linkages between economic, social and environmental factors, which promote green entrepreneurship and pave way for sustainable development in the long run. Hereafter, the study takes up case studies from successful green business initiatives in India to look into the motivation and success factors of green entrepreneurship in Indian markets. In conclusion, suggestions are offered to overcome bottlenecks and foster green entrepreneurship

\section{Enabling factors of green entrepreneurship}

It is important to do an in-depth study of the factors and conditions that impact green entrepreneurship and impact of formal and informal networks on the performance of green small and medium enterprises (SMEs) (Qazi et al., 2020). Starting a business is riskier in transition economies than in developed economies, which is why a higher level of entrepreneurial creativity and more friendly economic ecosystem is required to reduce failure and risks (Haldar, 2019) There is a need to define green entrepreneurship and its attributes in a shared manner (Demirel et al., 2019). To promote green entrepreneurship, it is important that governments provide friendly policy frameworks, reduce/ remove corruption to make it more attractive and educate consumers about the importance of consuming green products (Melay et al., 2017). Environmental knowledge has strong positive association to green purchase behavior, therefore in order to induce green entrepreneurship it is important to make people environmentally aware, which in turn will lead to people buying green product irrespective of the higher prices (Grilli et al., 2018). A green entrepreneur will be more likely to attract venture capitalists if he is able to send a reliable signal to investors, which will not only be done by making use of 
green technologies and positioning the venture at the same time in green sector (Soomro et al., 2020). Environmental values have a positive impact on the success of green entrepreneurial activities; people with concern towards environment are asset to the completely green entrepreneurial ecosystem (Tien, 2020). There is a need to promote green entrepreneurship by incentivizing investments in green business practices and reducing bottlenecks in the development of sustainable market scenario in India (Haldar, 2019). Green enterprises require more multidimensional and multilevel support in comparison to commercial enterprises therefore to induce willingness and readiness towards starting these, government should create favorable conditions including information sharing, financial incentivization, information exchange and knowledge enhancement measures (Tien, 2020).

For green initiatives and green entrepreneurship to succeed an enabling ecosystem is required that contains components that do not have any definitive boundaries, and are dynamic, interacting and correlating (Moriggi, 2020). In India few of the major challenges green entrepreneurs face is raising of funds, lack of access to informational sources, lack of legal awareness and managerial and technical expertise (Moriggi, 2020).

\section{Research Objectives and Methodology}

The aim of this study is to understand and analyze the development of green entrepreneurship in India. Therefore, following objectives have been set:

- To define 'green entrepreneurship'.

- To study the enablers of green entrepreneurship in India.

- To offer suggestions to promote green entrepreneurship India.
This study explores the concept of 'green entrepreneurship' using all the available secondary literature sources such as research papers, web pages of green enterprises and interviews of green innovators available on print and digital media. Based on the literature available, a conceptual model is derived which analyses the nexus between social, environmental and economic factors in shaping green entrepreneurship in the Indian markets.

\section{Conceptual \\ Model: \\ entrepreneurship as a source of Competitive Advantage for the firms and Sustainable development for the economy}

The continuous and growing depletion of natural reserves, increase in global temperature, increase in Green House gas emissions, environment pollution and ecosystem and rapidly endangering of biodiversity has lead policy makers and institutions of both global and national stature to enact laws to penalize enterprises that are causing major harm to the environment and incentivize firms that are engaged in green innovation, use of green technology and production of green products. Growing awareness among consumers about environmental preservation has created green markets that demand products produced using green technologies, redesigning of supply chain in tandem with green agenda, creating new opportunities for green entrepreneurship. The enterprises that are focusing on green management practices therefore have an edge that these can swiftly build into competitive advantage thus paving way for other firms that would make other firms to follow the green practices ultimately leading to sustainable development.
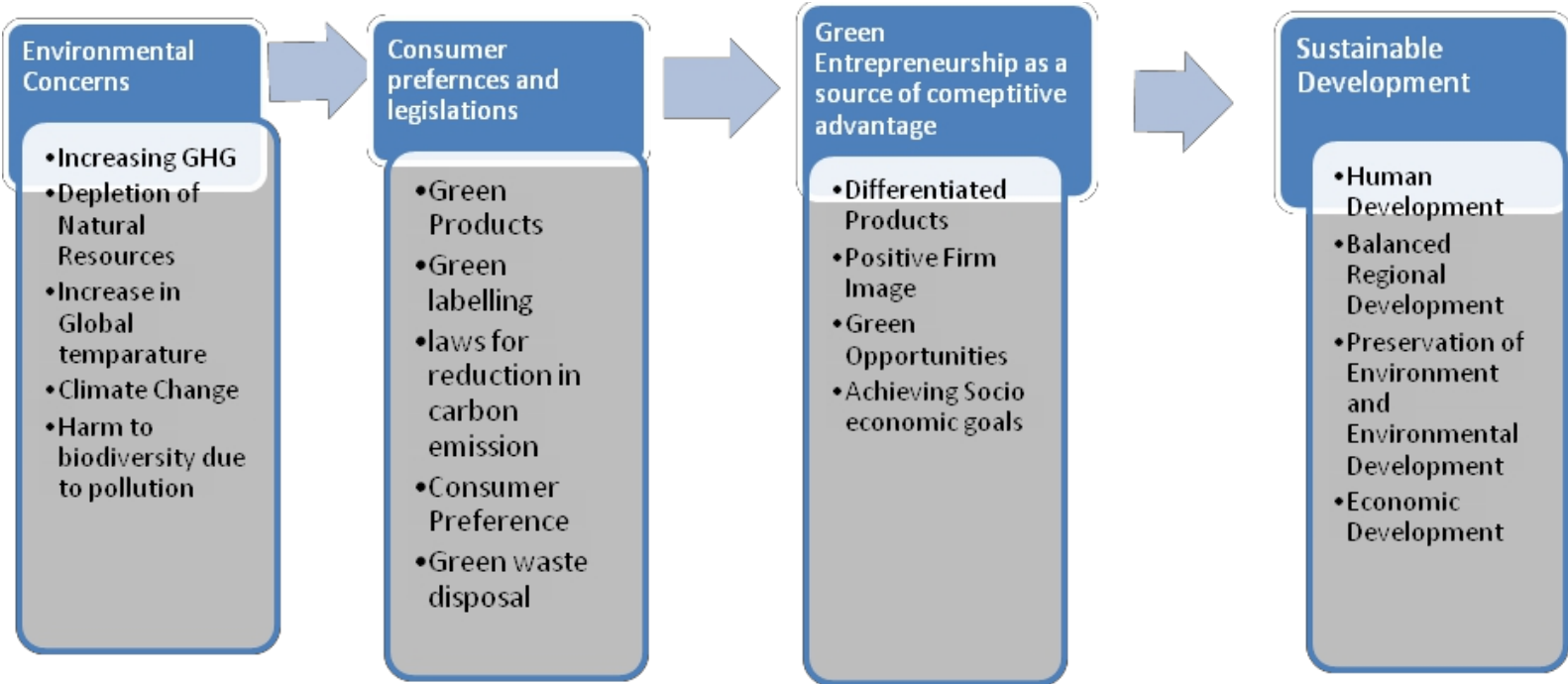

Fig. 1. Nexus between environmental, consumer and institutional, green opportunities and sustainable development.

Source: Author's Compilation 


\section{Green Entrepreneurs in India}

\section{Mini Couture (MINC)}

MINC is clothing label started by Mini Shibu and Kochery C Shibu in 2007, that designs and produces both contemporary and classic clothes based on the concept of fair wages, low carbon footprints, natural fabrics, environment friendly dyes and packaging material made up of wood, coconut and sea shell. MINC uses Khadi sourced from SOFA (Sittilingi Organic Farmers Association) through an NGO by name Tribal Health initiative.

\section{Fourth Partner Energy}

Started by Saif DHorajiwala, Vivek Subramanian and Vikas Gulati in 2010, Fourth Partner Energy is a Hyderabad based firm, committed to providing green electricity to every Indian Business. The firm helps firms in reducing their carbon footprints and meeting sustainability targets- while ensuring cost benefits of 30-60\% on electricity consumed, by offering range of offsite and onsite energy options to choose from. Fourth Partner Energy has tripartite goals i.e. helping businesses in: reducing cost of energy, reducing carbon emissions and becoming power independent. The company has so far installed solar capacity of $251 \mathrm{MWp}$. Using equity funding and debt, this firm has been able to undertake capacity addition and growth plans. Honeywell, NTPC, Airtel, Bharathi Cement, BridgeStone, Axis Banks, ICICI Bank, Glenmark, Ferrero are some clients of the rapidly expanding client base of FPEPL. In March 2021, the firm announced its partnership with Indika Energy, a Malaysian firm to provide solar, battery storage and EV solutions to the South East Asian nation.

\section{Digital Green}

Digital Green started as a Microsoft Project for finding out if there is a role of technology in helping small-scale farmers in 2006 in India. It is established to empower farmers, by helping them with the technological knowledge and information sharing to enhance their agricultural produce. The organization has so far reached 15200 villages and has helped 19 million people of which $90 \%$ are women.

\section{Conclusion and Suggestions}

The study throws light on the concept of green entrepreneurship that uses green technologies in production and redesigns supply chains to make these more responsive to the necessities of greenness, create green jobs and enhance the demand for green products leading to sustainable development and greener economy. There is a need to create a culture that promotes the awareness among entrepreneurs regarding opportunities arising out of adoption of green business models, incentivizing green investments and removing the bottlenecks in the process of starting and sustaining green businesses.
Specific institutional support is also needed to provide green entrepreneurs with financial and technical support. Green enterprises require more multidimensional and multilevel support in comparison to commercial enterprises therefore to induce willingness and readiness towards starting these; government should create favorable conditions including information sharing, financial incentivization, and information exchange and knowledge enhancement measures.

\section{References}

Demirel, P., Li, Q.C., Rentocchini, F. and Tamvada, J.P. 2019. Born to be green: New insights into the economics and management of green entrepreneurship. Small Busi. Econ. 52(4): 759-771.

https://doi.org/10.1007/s11187-017-9933-Z

Grilli, L., Mrkajic, B. and Latifi, G. 2018. Venture capital in Europe: social capital, formal institutions and mediation effects. Small Busi. Econ. 51(2): 393-410. https://doi.org/10.1007/s11187-018-0007-7

Haldar, S. 2019. Green entrepreneurship in theory and practice: insights from India. Int. J. Green Econ. 13(2): 99-119. https://doi.org/10.1504/IJGE.2019.103232

Melay, I., O'Dwyer, M., Kraus, S. and Gast, J. 2017. Green entrepreneurship in SMEs: a configuration approach. Int. J. Entrepre. Ventur. 9(1): 117. https://doi.org/10.1504/IJEV.2017.082630

MINC ecofashion - Your one stop clothing shop for all things eco-friendly (mincecofashion.com). India's Leading Distributed Solar Energy Company (fourthpartner.co) Digital Green.

Moriggi, A. 2020. Exploring enabling resources for place-based social entrepreneurship: a participatory study of Green Care practices in Finland. Sustain. Sci. 15(2): 437-453. https://doi.org/10.1007/s11625-019-00738-0

Qazi, W., Qureshi, J.A., Raza, S.A., Khan, K.A., and Qureshi, M.A. 2020. Impact of personality traits and university green entrepreneurial support on students' green entrepreneurial intentions: the moderating role of environmental values. J. Appl. Res. Higher Edu. 13(4): 1154-1180. https://doi.org/10.1108/JARHE-05-2020-0130

Schumpeter, J. 1942. Creative destruction. Capitalism, socialism and democracy. Harper \& Brothers, New York. 431p.

Soomro, R.B., Mirani, I.A., Ali, M.S. and Marvi, S. 2020. Exploring the green purchasing behavior of young generation in Pakistan: opportunities for green entrepreneurship. Asia Pacific J. Innov. Entrepren. 14(3): 289302. https://doi.org/10.1108/APJIE-12-20190093

Tien, N.H., Hiep, P.M., Dai, N.Q., Duc, N.M. and Hong, T.T.K. 2020. Green entrepreneurship understanding in Vietnam. Int. J. Entrepren. 24(2): 1-14. 